\title{
LEAN MANUFACTURING PERCEPTIONS AND ACTUAL PRACTICE AMONG MALAYSIAN SME'S IN AUTOMOTIVE INDUSTRY
}

\author{
A.N.M. $\operatorname{Rose}^{1,2, a}$, B. Md. Deros ${ }^{2, b}$ and M.N. Ab. Rahman ${ }^{2, c}$ \\ ${ }^{1}$ Faculty of Mechanical Engineering, University Malaysia Pahang, \\ 26600 Pekan, Pahang, Malaysia \\ Email: nasser@ump.edu.my \\ Phone: +6094246348; Fax: +609424622 \\ ${ }^{2}$ Faculty of Engineering and Built Environment, \\ Department of Mechanical and Material Engineering, Universiti Kebangsaan Malaysia, \\ 43600, UKM, Bangi, Malaysia
}

\begin{abstract}
Stiff business challenges and product competition faced by automotive component manufacturers has forced them to look into lean manufacturing (LM). Presently there are more than 100 LM practices. However, small and medium enterprises (SMEs) are not able to implement all LM practices due to financial, expertise and skill constraints. Therefore, in this study the authors investigated the level of perception and actual practice within $24 \mathrm{LM}$ practices, regarding actions believed feasible to be implemented in SMEs. In addition, the authors gathered LM information sources, reasons for implementing LM and its benefits to SMEs. A questionnaire survey was conducted in 35 SMEs involves in manufacturing automotive components. The majority of SMEs have a high perception of the importance of LM practices but in reality are not undertaking them. The SMEs mainly received their LM information from their customers, and they strongly believe that LM practices could improve their long-term business sustainability and competitiveness in the market place.
\end{abstract}

Keywords- Lean manufacturing; SME, automotive; lean perception; lean practices.

\section{INTRODUCTION}

SMEs have played a tremendous role in the manufacturing sector all over the world. In the $2007,96 \%$ of Malaysian organisations were SMEs, which contributed $30.7 \%$ of the total manufacturing output and $26.3 \%$ of total value added products (SME Development Council, 2007). In Malaysia, SMEs are defined as companies with between 5 and 150 full-time employees and annual sales turnover between RM251k to RM25 million (SME Development Council, 2007). In order to be at par with large and well-established foreign automotive manufacturers, Malaysian SMEs involved in manufacturing automotive components have to implement and practice LM to achieve manufacturing excellence (Womack et al., 1990). It is suggested that in the $21^{\text {st }}$ century all SMEs implement and practice LM to gain its benefits for their organisations (Dankbaar, 1997; Rineheart et al., 1997). Among the benefits offered by LM are that it acts as a cost reduction mechanism and can be used as a guide to SMEs to become world-class organisations (Papadopoulu and Ozbayrak, 2005). The two main objectives of this paper are: first, to investigate the level of Malaysian SMEs understanding of LM practices and the extent of LM implementation in their organisations. Secondly, the respondents were 
also asked about their sources of information on LM, the reasons for and benefits of LM implementation and practice.

\section{LITERATURE REVIEW}

There are many LM practices and techniques available that can be practiced by industries (Pavnaskar et al., 2003). The benefits that can be achieved by implementing LM manufacturing practices and techniques are cost reductions, on-time delivery, and reductions in inventory and cycle time (Bhasin and Burcher, 2006; Ferdousi and Ahmed, 2009; Shah and Ward, 2003). In addition, LM is able to provide a more superior method of waste elimination and products manufacture (Womack and Jones, 2003). The literature shows that numerous publications have strongly proposed that organisation should implement comprehensive LM practices to gain the above-stated benefits (Liker, 2004; Meier and Forrester, 2002).

However, the literature shows that SMEs are not capable of implementing all LM practices at once (Gunasekaran et al., 2000). The alternative in SMEs is to run feasible LM practices sequentially, starting from the easiest or cheapest (Lee, 2004). This approach could minimise the financial burden on the SMEs and thus maximise their employees' commitment towards implementing LM practices. In addition, SMEs could select and implement the most feasible practice to act as a stepping stonee to becoming a LM enterprise (Herron and Braiden, 2007). To do this, the authors have reviewed many highly-cited journals and discovered 16 highly-recommended LM practices in their papers (Crawford and Cox, 1991; Fullerton and McWatters, 2001; Gyampah and Gargeya, 2001; Lee, 1997; Lee and Ebrahimpour, 1984; Matsui, 2007; Mehra and Inman, 1992; Ohno, 1998; Panizzolo, 1998; Sakakibara et al., 1997; Schonberger, 1982; Shah and Ward, 2007; White et al., 1999; Womack et al., 1990; Zhu and Meredith, 1995). The most highlighted LM practices are a reduction in set up time, kanban, small lot size, supplier management, preventive maintenance, multifunction employees, uniform workload, visual control, employee involvement (quality circles), total quality management, training, teamwork, production smoothing, continuous improvement, 5S and standardisation. According to Narang (2008), the literature identifies the three most implemented LM practices as being a reduced set up time, kanban and small lot size, which are critical in ensuring LM implementation success. Failure to implement these practices efficiently may result in production delays and an inability to maintain continuous flow. On the other hand, the least suggested LM practices are 5S and standardisation. A high level of understanding of LM is very important to successfully implement them in practice. Therefore, in this paper, the authors would like to investigate the level of SMEs' understanding of LM practices and then translate their understanding into actual implementation.

\section{METHODOLOGY}

The research methodology used was survey questionnaire. The questionnaire consists of five parts. The first part asked about the respondents' background. The second part queried the SME's perception and level of practice of 24 LM practices. This paper presents the results of the best 14 practices as chosen by the respondents. In this part, the respondents were asked to rate two aspects (perception and practice) using a 5-point Likert scale. The rating scales for the perceived importance range from: 1 - not important to 5 - very important. Meanwhile, the rating scales for the level of practice 
range from: 1 - no implementation to 5 - highly implemented. In the third section, the respondents were asked how they implemented LM practices in their SMEs. In the fourth section, the respondents were asked how they acquired LM information. In the final section, respondents were asked, based on their real experience, the benefits of LM implementation. All questions in the survey questionnaire were developed so that they are in a close ended form. The survey questionnaire was developed based on an extensive literature review (Shah and Ward, 2007). Later, it was checked and validated by 10 experts, comprising of academics and industry practitioners.

\section{RESULTS AND ANALYSIS}

Initially 250 questionnaires were distributed by post and electronic mail to potential respondents. Unfortunately, only 27 completed and useable questionnaires were returned by the respondents, thus giving a poor response rate of $10.8 \%$. Due to this poor result, the authors decided to contact the Vendor Development Department of the Malaysian car manufacturers to garner some support from them. In March 2011, the authors' application was approved, and a time slot offered during a vendor briefing program and annual quality presentation. On that day, the authors personally distributed the survey questionnaire to all participants and asked them to fill in the questionnaire based on their actual experience of LM implementation. Returned questionnaire without complete information will not be considered for statistical analysis. At the end of the program the authors received 70 sets of completed survey questionnaires, raising the total number of completed and returned survey questionnaires to 97.

Table 1. SME profiles

\begin{tabular}{llll}
\hline Descriptive & & Freq. & \% \\
\hline Type of ownership & Malaysian & 28 & 80.0 \\
& Foreign & 4 & 11.4 \\
& Joint venture & 3 & 8.6 \\
& & & \\
Type of products & Metal & 11 & 31.4 \\
& Plastics & 12 & 34.3 \\
& Electronics & 1 & 2.9 \\
& Rubber & 4 & 11.4 \\
& Mechanical & 2 & 5.7 \\
& Others & 5 & 14.3 \\
& & & \\
No. of years established & $<5$ & 5 & 14.3 \\
& $5-10$ years & 10 & 28.6 \\
& $>10$ and $<15$ & 8 & 22.9 \\
& $>15$ & 12 & 34.3 \\
& & & \\
No. of years implement & $<3$ & 21 & 60.0 \\
lean (years) & & & \\
& $>3$ and $<5$ & 11 & 31.4 \\
& $>5$ & 3 & 8.6 \\
\hline
\end{tabular}


As a result, the response rate increased from 10.8 to $38.8 \%$, which is considered adequate to perform SPSS analysis. The respondents' profile indicates that $63.9 \%$ of them were from large companies and $36.1 \%$ were from SMEs. The majority of respondents were from large companies, and the results of this survey were similar to the results of Shah and Ward (2007) and Wong et al. (2009). In this paper, the authors wanted to highlight LM implementation in SMEs manufacturing automotive components.

Table 1 shows the SME's profiles. The survey results showed that a large majority (i.e. 80\%) of the SMEs are owned by Malaysians. The two main products manufactured comprised of metal with $31.4 \%$ and plastics $(34.3 \%)$. Almost $86 \%$ of the respondent SMEs were established for more than 5 years. Sixty percent of them have less than 3 years experience and are considered new in LM implementation. The objective of this paper is to examine and compare SMEs' perceptions and practices with respect to LM implementation. In this paper, the authors shall discuss 14 highly perceived and practiced LM practices chosen by the survey respondents, shown in Table 2. The three highest mean scores for perceived importance of LM practice are $5 \mathrm{~S}$, continuous improvement and reduced machine set up time. The survey results show that the understanding of the importance of LM practices were translated into real practice, except for the reduced machine set up time, which is in $7^{\text {th }}$ place instead of $3^{\text {rd }}$. The $3^{\text {rd }}$ ranking for practiced LM was the standardisation of operation. The outcome of this survey may inform us that the top priority for LM practice implementation in SMEs is related to cost reduction, which is in line with the conclusions of Lee (1997) and Gunasekaran et al. (2000). As shown in Table 2, the majority of SMEs agreed that the four highest practices implemented are 5S, continuous improvement (Kaizen), reducing machine set-up time and the standardisation of operation. Apart from cost reductions, these four practices were considered as fundamental to LM manufacturing and are easy to implement in SMEs. In addition, 5S and continuous improvement implementation results can be achieved almost immediately when compared to others that require a long time to see the results.

Table 2. Rank of mean scores for perception and practice of LM practices

\begin{tabular}{lcccc}
\hline \multirow{2}{*}{ LM practice } & \multicolumn{2}{c}{ Perceived } & \multicolumn{2}{c}{ Practiced } \\
\cline { 2 - 5 } & Mean & Rank & Mean & Rank \\
\hline 5S & 4.800 & 1 & 3.943 & 1 \\
Continuous improvement (Kaizen) & 4.714 & 2 & 3.914 & 2 \\
Reduce machine set up time & 4.714 & 3 & 3.686 & 7 \\
Standardisation of operation & 4.600 & 4 & 3.886 & 3 \\
Improvement team activities & 4.543 & 5 & 3.657 & 8 \\
Plan Do Check Action (PDCA) & 4.543 & 6 & 3.857 & 4 \\
Visual control - Display charts & 4.514 & 7 & 3.686 & 5 \\
Preventive maintenance program & 4.486 & 8 & 3.486 & 10 \\
Kanban & 4.429 & 9 & 3.029 & 14 \\
Multifunction/multiskilling & 4.400 & 10 & 3.686 & 6 \\
employees & & & & \\
Quality circle & 4.400 & 11 & 3.400 & 12 \\
Statistical process control (SPC) & 4.371 & 12 & 3.457 & 11 \\
Value stream mapping (VSM) & 4.343 & 13 & 3.600 & 9 \\
TAKT time & 4.314 & 14 & 3.286 & 13 \\
\hline
\end{tabular}


Referring to Table 2, multifunction/multiskilling employees is ranked in $6^{\text {th }}$ place. However it is quite surprising that the implementation of quality circles in SMEs is ranked in $10^{\text {th }}$ place. Possible reasons may be that the implementation of quality circles not seriously considered in SMEs due to the low numbers of employees, and that they already treated their employees well, are easy to manage and do not need a lot of bureaucracy (Antony and Kumar, 2005). Under these circumstances, any changes that the SMEs want to make can be done quickly and easily with the full support of their employees. The subsequent analysis was done using SPSS Version 18 to determine whether there is any significant difference between the SMEs' perceptions and the practice of LM procedures. The non-parametric test - the Wilcoxon test - was applied to analyse the statistical outcome. Table 3 shows that the Wilcoxon test results for the $14 \mathrm{LM}$ perceptions and practices have a $\mathrm{p}$ value of less than $0.05(\mathrm{p}<0.05)$, which means there are significant differences between the SMEs' perceptions and practices. Thus it can be concluded that SMEs have a high perception of importance towards the 14 LM practices, however they fail to translate this high perception of importance into actual practice. The findings of this survey on LM perceptions and actual practice are in line with findings on total quality management and benchmarking studies carried out on SMEs (Deros et al., 2004; Zadry and Yusof, 2006).

Table 3. Comparison between perception and actual practice using Wilcoxon test

$$
(\mathrm{n}=35)
$$

\begin{tabular}{lcc}
\hline \multicolumn{1}{c}{ Lean practices } & $\mathrm{p}$ & $\mathrm{Z}$ \\
\hline Reduced machine/tooling set up time & 0.000 & -4.485 \\
Standardisation of operation & 0.000 & -3.987 \\
Kanban & 0.000 & -4.622 \\
Continuous improvement (Kaizen) & 0.000 & -4.007 \\
5S & 0.000 & -4.144 \\
Quality circle & 0.000 & -4.419 \\
Multifunction/multiskilling employees & 0.000 & -3.801 \\
Improvement team activities & 0.000 & -4.274 \\
Preventive maintenance program & 0.000 & -4.618 \\
Visual control - Display charts & 0.000 & -4.007 \\
Value stream mapping (VSM) & 0.003 & -4.289 \\
TAKT time & 0.000 & -4.448 \\
Plan Do Check Action (PDCA) & 0.000 & -3.738 \\
Statistical process control (SPC) & 0.000 & -4.413 \\
\hline
\end{tabular}

The respondents were also asked about the origin of the sources of LM information in their SMEs. Figure 1 shows the various information sources available to the respondents. The four highest frequencies of sources of LM information are the organisation's customers, followed by top management, government agencies and seminars. In order to ensure successful LM implementation in Malaysian automotive component manufacturers, all parties must be involved; which includes all $1^{\text {st }}$ tier, $2^{\text {nd }}$ tier, and $3^{\text {rd }}$ tier vendors, and they should play a role in supporting LM practice implementation (Real et al., 2007). Commitment from the SMEs' top management and government agencies, especially in terms of financial support, could also influence LM implementation success (Achanga et al., 2006). Meanwhile, the involvement of a government agency could enhance the SMEs' participation in LM implementation by 
providing them with financial assistance. The Malaysian Automotive Institute (MAI) is a government agency that coordinates LM implementation among automotive component manufacturers. This agency employs senior technical experts in LM from Japan to train Malaysian SMEs in LM. This seven years program started in 2006 and lasts until 2013, up till now 87 SMEs have participated in this training program (MAI, 2012).

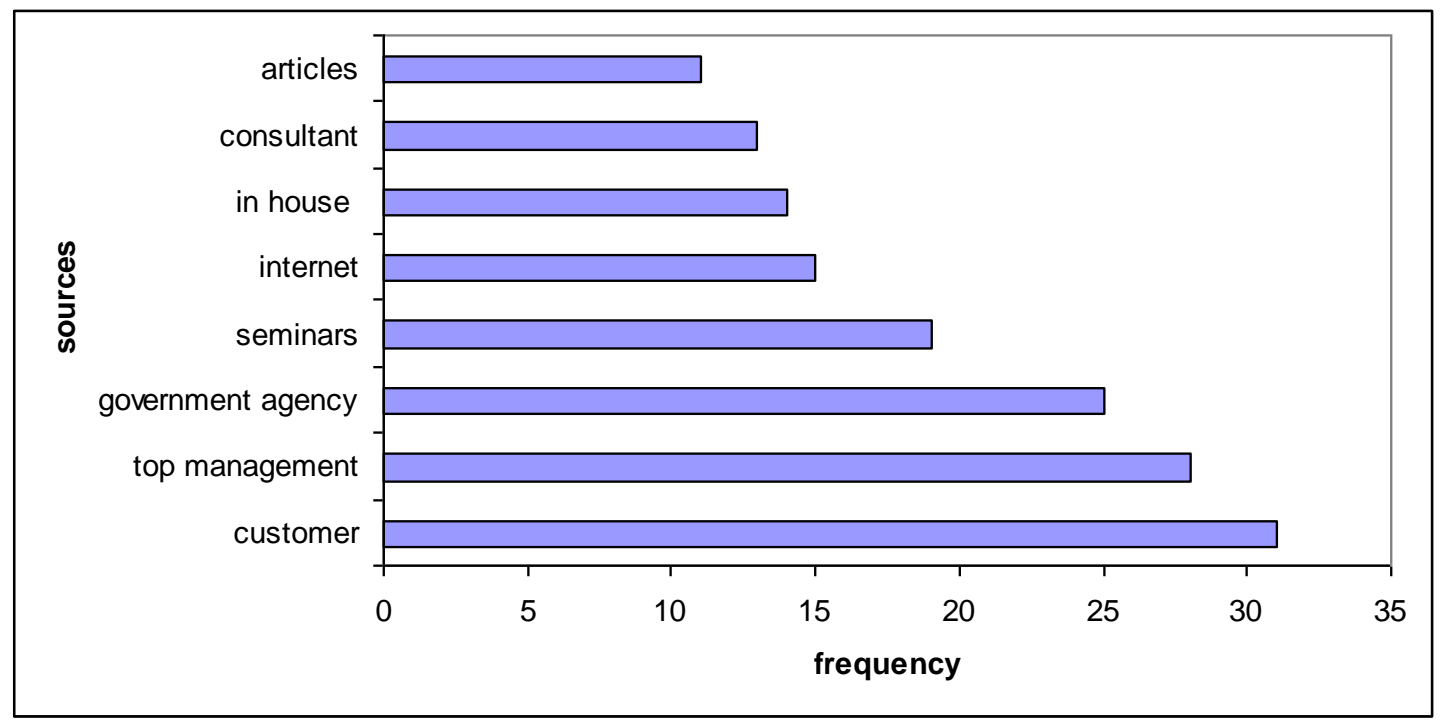

Figure 1. Lean manufacturing information sources.

In the fifth section of the questionnaire, the respondents were asked the reasons why they are implementing LM in their SMEs. Figure 2 shows the reasons given by respondents in choosing LM. The three most common reasons are:

i) to improve long-term cost competitiveness

ii) to meet customer demand

iii) to improve long-term quality competitiveness

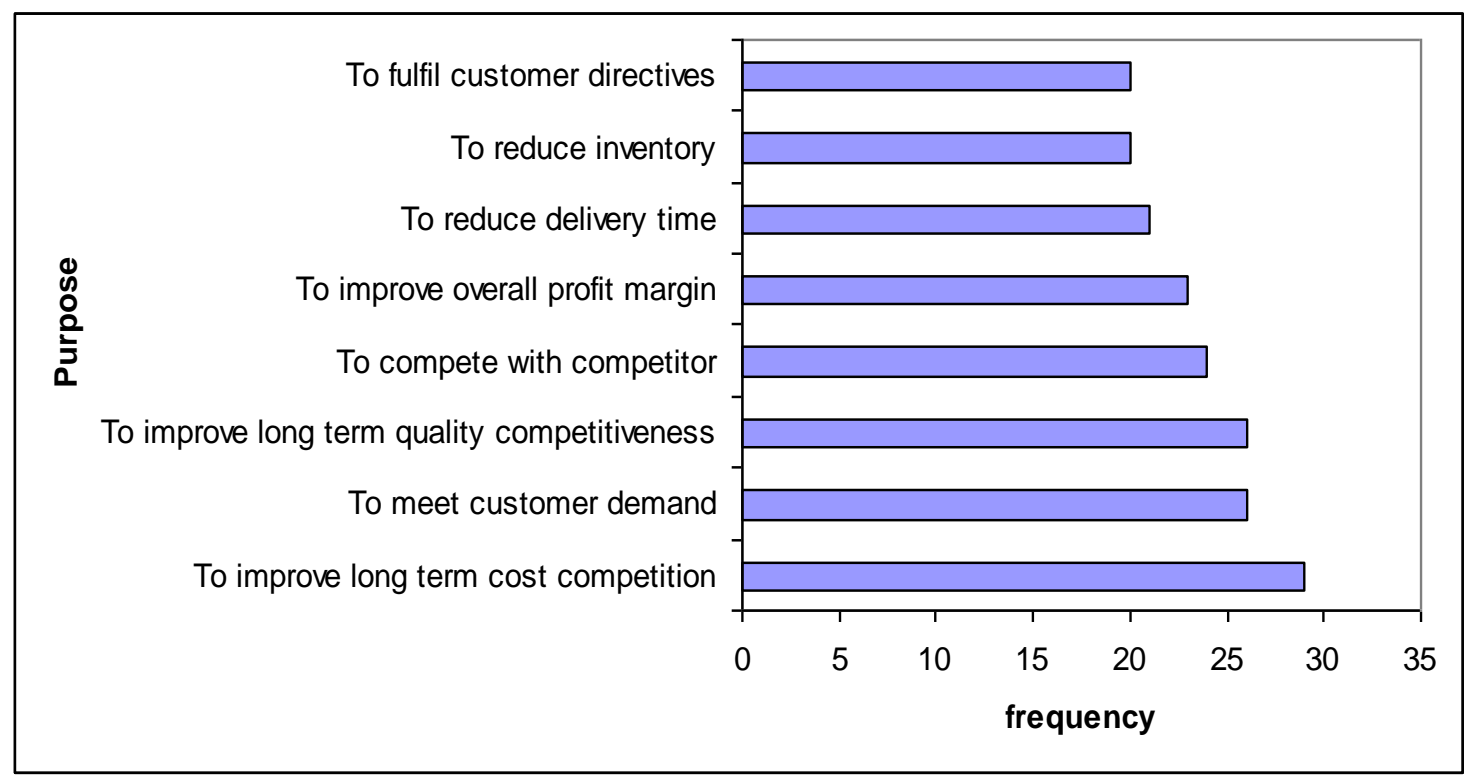

Figure 2. Reasons for chosing LM. 
Most of these reasons are related to the customers' requirements, who always demand that their vendors improve quality and reduce costs. According to Katayama and Bennete, (1996), improvements in customer satisfaction would increase the chance of becoming a long-term supplier. In addition, these efforts could raise the status of SMEs to become at par with larger companies. Failure to meet customer requirements may result in a loss of both current and future business opportunities to competitors. In the final part, the respondents were asked to identify the benefits gained from LM implementation in their SMEs. In this part the respondents were asked to rate the level of benefits based on a 5-point Likert scale. The score will be 5 if the respondents strongly agree on the highlighted benefits, whereas if they strongly disagree the score is 1. Figure 3 shows the 10 benefits considered in the questionnaire. The three highest mean values of benefits are floor space utilisation, production lead time and finished goods inventory. The highest score is 3.9 for floor space utilisation. The floor space was minimised through a reduction in travel distance between one workstation and another. Travel distance is considered one of 7 wastes of time in LM (Melton, 2005). A shorter travel distance will lead to a reduction in lead time. In addition, the respondents also claimed that LM implementation results in a better finished goods inventory. This result is in line with that of Matson and Matson (2007), who discovered that more than half of their respondents claimed that the level of the inventory was enhanced after LM implementation.

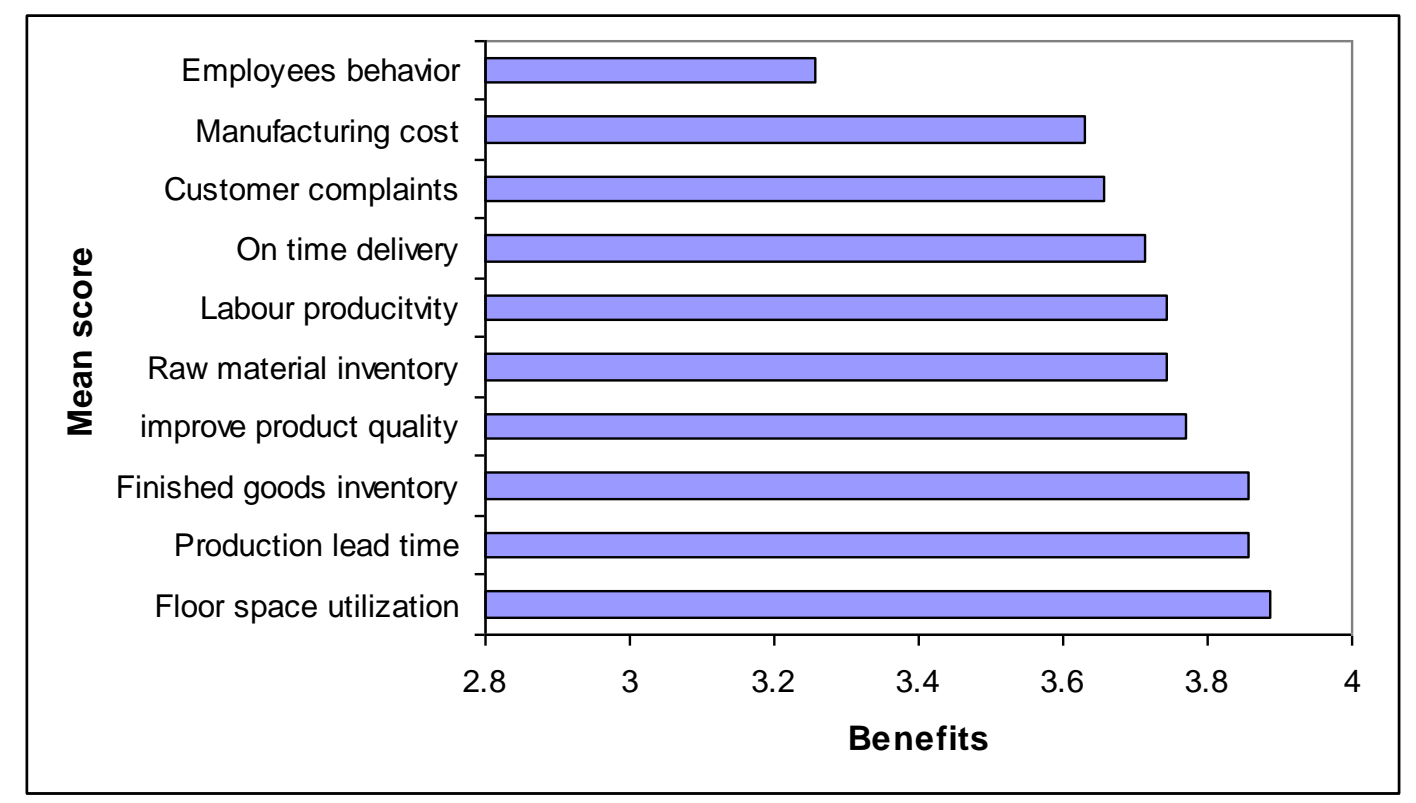

Figure 3. Mean score for lean benefits

\section{CONCLUSION}

This paper has provided useful information related to the current status of LM implementation in Malaysian SMEs involved in the automotive component manufacturing industry. In addition, it also highlighted some critical issues with respect to LM implementation in SMEs. This study shows that SMEs' top management is aware on the importance of LM implementation in their companies. The movement of 
Malaysian SMEs towards LM is in line with the Asian Free Trade Agreement (AFTA), which will be fully enforced in 2015 (MAI). The majority of the survey respondents have high perceptions on the importance of LM practices; however it was determined from the survey that the level of actual LM implementation and practice is still low. The significant difference between the perceptions of importance and actual practice may be due to the respondents' lack of authority or due to their failure to translate what they perceived as being important to actual practice. Therefore, SME top management needs to seriously look into this matter in order to ensure that the high perceptions of importance of LM practices are being translated into actual practice on the shop floor. Apart from that, the survey also discovered that the majority of SMEs mainly received LM information from their customers, top management and government agencies. Moreover, the majority of SMEs that participated in this survey were struggling to improve their long-term cost competition, which can be achieved through LM implementation.

\section{ACKNOWLEDGEMENT}

The authors would like to thank Proton Berhad for supporting this research.

\section{REFERENCES}

Achanga, P., Shehab, E., Roy, R. and Nelder, G. 2006. Critical success factors for lean implementation within SMEs. Journal of Manufacturing Technology Management, 17(4): 460-471.

Antony, J. and Kumar, M. 2005. Six sigma in small and medium sized UK manufacturing enterprises. International Journal of Quality and Reliability Management, 22(8): 60-874.

Bhasin, S. and Burcher, P. 2006. Lean viewed as a philosophy. Journal of Manufacturing Technology Management, 17(1): 56-72.

Crawford, K.M. and Cox, J.F. 1991. Addressing manufacturing problems through the implementation of just in time. Production and Inventory Management Journal, 32(3): $1-4$.

Dankbaar, B. 1997. Lean production: denial, confirmation or extension of sociotechnical systems design? Human Relations, 50(5): 567-585.

Deros, B.M., Yusof, S. and Salleh, A.M. 2004. Perceptions and practices of critical success factors in benchmarking implementation in Malaysian automotive manufacturing companies. Journal of Quality Measurement and Analysis, 2(1): 45-61.

Ferdousi, F. and Ahmed, A. 2009. An investigation of manufacturing performance improvement through lean production: a study on Bangladeshi garment firms. International Journal of Business and Management, 4(9): 106-114.

Fullerton, R.R. and McWatters, C.S. 2001. The production performance benefits from JIT implementation. Journal of Operations Management, 19: 81-96 .

Gunasekaran, A., Forker, L. and Kobu, B. 2000. Improving operations performance in a small company: a case study. International Journal of Operations and Production Management, (20)3: 316-335.

Gyampah, K. and Gargeya, V. 2001. Just-in-time manufacturing in Ghana. Industrial Management and Data Systems, 101(3): 106-113. 
Herron, C. and Braiden, P.M. 2007. Defining the foundation of lean manufacturing in the context of its origin. Agile Manufacturing, ICAM, 148-157.

Katayama, H. and Bennete, D. 1996. Lean production in a changing competitive world: a Japanese perspective. International Journal of Operations and Production Management, 16(2): 8-23.

Lee, C.Y. 1997. JIT adoption by small manufacturers in Korea. Journal of Small Business Management, 35(3), 98-107.

Lee, C.Y. 2004. TQM in small manufacturers: an exploratory study in China. International Journal of Quality and Reliability Management, 21(2), 175-197.

Lee, S.M. and Ebrahimpour, M. 1984. Just-in-time production system: some requirements for implementation. International Journal of Operations and Production Management, 4(4): 3-15.

Liker, J.K. 2004. The Toyota Way - 14 Management Principles from the World's Greatest Manufacturer. New York: McGraw-Hill.

MAI(Malaysian Automotive Institute). 2012. [online] http://www.mai.org.my/ver1/ index.php?option=com_contentandview $=$ categoryandid=91 andItemid= 154). Accessed on 12 December 2012.

Matson, J.E. and Matson, J.O. 2007. Just-in-time implementation issues among automotive suppliers in the southern USA. Supply Chain Management: An International Journal, 12(6): 432-443.

Matsui, Y. 2007. An empirical analysis of just-in-time production in Japanese manufacturing companies. International Journal Production Economics, 108: 153-164.

Mehra, S. and Inman, R.A. 1992. Determining the critical elements of just-in-time implementation. Decision Science, 23(1): 160-174.

Meier, H. and Forrester, P. 2002. A model for evaluating the degree of leanness of manufacturing firms. Integrated Manufacturing Systems, 13(2), 104-109.

Melton, T. 2005. The benefits of lean manufacturing. What lean thinking has to offer the process industries. Chemical Engineering Research and Design, 83(A6): 662-673.

Narang, R.V. 2008. Some issues to consider in lean production. First International Conference on Emerging Trends in Engineering and Technology, pp. 749-753.

Ohno, T. 1988. The Toyota Production System [English translation]. Productivity Press.

Panizzolo, R. 1998. Applying the lessons learned from 27 lean manufacturers. The relevance of relationships management. International Journal Production Economics, 55: 223-240.

Papadopoulu, T.C. and Ozbayrak, M. 2005. Leanness: experiences from the journey to date. Journal of Manufacturing Technology Management 16(7): 784-806.

Pavnaskar, S.J., Gershenson, J.K. and Jambekar, A.B. 2003. Classification scheme for lean manufacturing tools. International Journal Production Research, 41(13): 3075-3090.

Real, R., Pralus, M., Pillet, M., and Guizzi, L. 2007. A study of supporting programs for small and medium: a first stage going to "lean". IEEE International Conference on Industrial Engineering and Engineering Management, pp. 515-519.

Rineheart, J., Huxley, C., Robertson, D. 1997. Just Another Car Factory? Lean Production and its Contents. Cornell University Press.

Sakakibara, S., Flynn, B.B., Schroeder, R.C. and Morris, W.T. 1997. The impact of justin-time manufacturing and its infrastructure on manufacturing performance. Management Science, 43(9): 1246-1257. 
Schonberger, R.J. 1982. Japanese manufacturing techniques: nine hidden lessons in simplicity. New York: Free Press.

Shah, R. and Ward, P.T. 2003. Lean manufacturing context, practice bundles and performance. Journal of Operations Management, 21(12): 129-149.

Shah, R. and Ward, P.T. 2007. Defining and developing measures of lean production. Journal of Operations Management, 25(4), 785-805.

SME Development Council 2007. SME Annual Report 2007. Malaysia national SME development council, Malaysia.

White, R.E., Pearson J.N. and Wilson J.R. 1999. JIT manufacturing: a survey of implementations in small and large U.S. manufacturers. Management Science, 45(1): 1-14.

Womack, J.P. and Jones, D.T. 2003. Lean Thinking: Banish Waste and Create Wealth in Your Corporation. New York: Simon and Schuster.

Womack, J., Jones, D.T. and Roos, D. 1990. The Machine that Changed the World. New York: Rawson Associates.

Wong, Y.C., Wong, K.Y. and Ali, A. 2009. A study on lean manufacturing implementation in the Malaysia electrical and electronics industry. European Journal of Scientific Research, 38(4): 521-535.

Zadry, H.R. and Yusof, S.M. 2006. Total quality management and theory of constraints implementation in Malaysian Automotive Suppliers. Total Quality Management, 17(8): 99-1020.

Zhu, Z. and Meredith, P.H. 1995. Defining critical elements in JIT implementation: a survey. Industrial Management and Data Systems, 95(8): 21-28. 